\title{
A Rare Case Report of Unusual Path of Left Internal Jugular Central Line
}

\author{
Rajashekar Rangappa Mudaraddi ${ }^{\mathrm{a}}$ Hany Fawzi Greiss ${ }^{\mathrm{a}}$ \\ Navin Kumar Manickam ${ }^{b}$ \\ ${ }^{a}$ Department of Anaesthesiology, Rashid Hospital and Trauma Centre, Dubai, United Arab Emirates; ${ }^{b}$ Department of \\ Radiology, Rashid Hospital and Trauma Centre, Dubai, United Arab Emirates
}

\section{Keywords}

Anaesthesia $\cdot$ Emergency $\cdot$ Radiology · Superior venacava $\cdot$ Left atrium $\cdot$ Central line

\section{Abstract}

Central venous cannulation is the most common procedure performed in perioperative setting and intensive care unit. Many case reports reported unusual positioning of central line catheters. Here, we would like to report a case of central line path in persistent left superior vena cava, a rare entity with a course similar to the right internal jugular central line. Preoperative computed tomography chest showed duplex superior vena cava which was not reported.

(c) 2021 The Author(s)

Published by S. Karger AG, Basel

\section{Introduction}

Left-sided superior vena cava (SVC) occurs in 0.3$0.5 \%$ of the general population and in $5 \%$ of those with congenital heart defects. Persistent left superior vena cava
(PLSVC) is the most common congenital malformation of thoracic venous return [1]. Most patients are asymptomatic. In approximately $10-20 \%$ of cases, it is associated with drainage to the left atrium [1]. Most of the time, the presence of vessel is identified incidentally during central line placement as in our case or by computed tomography (CT)-chest. Written consent was obtained from the family of the patient.

\section{Case Report}

A 45-year-old male patient without comorbidities with the history of necrotizing pancreatitis posted for exploratory laparotomy. The preoperative vitals were stable. The patient had CT-chest and abdomen preoperatively with reports mostly concentrated on the abdomen. The patient had left internal jugular cannulation inserted using ultrasound in the first attempt with ease for inotrope and total parenteral nutrition. Surgery was uneventful; the patient was shifted to intensive care unit on ventilator support for further management. A chest X-ray done postoperatively revealed unusual course (Fig. 1), just like the straight course as in the right side. All ports have free venous blood, confirmed by blood gas analysis. Later, we consulted a radiologist who reported double SVC, which was not reported in previous CT-chest (Fig. 2). The patient was stable throughout in the intensive care unit.
(C) 2021 The Author(s)

Published by S. Karger AG, Basel

This article is licensed under the Creative Commons AttributionNonCommercial-NoDerivatives 4.0 International License (CC BYNC-ND) (http://www.karger.com/Services/OpenAccessLicense) Usage and distribution for commercial purposes as well as any distribution of modified material requires written permission.
Rajashekar Rangappa Mudaraddi Specialist Anaesthesiologist Rashid Hospital and Trauma Centre PO Box-4545, Oud Maitha Street, Dubai (United Arab Emirates) raj123doc@yahoo.co.in 


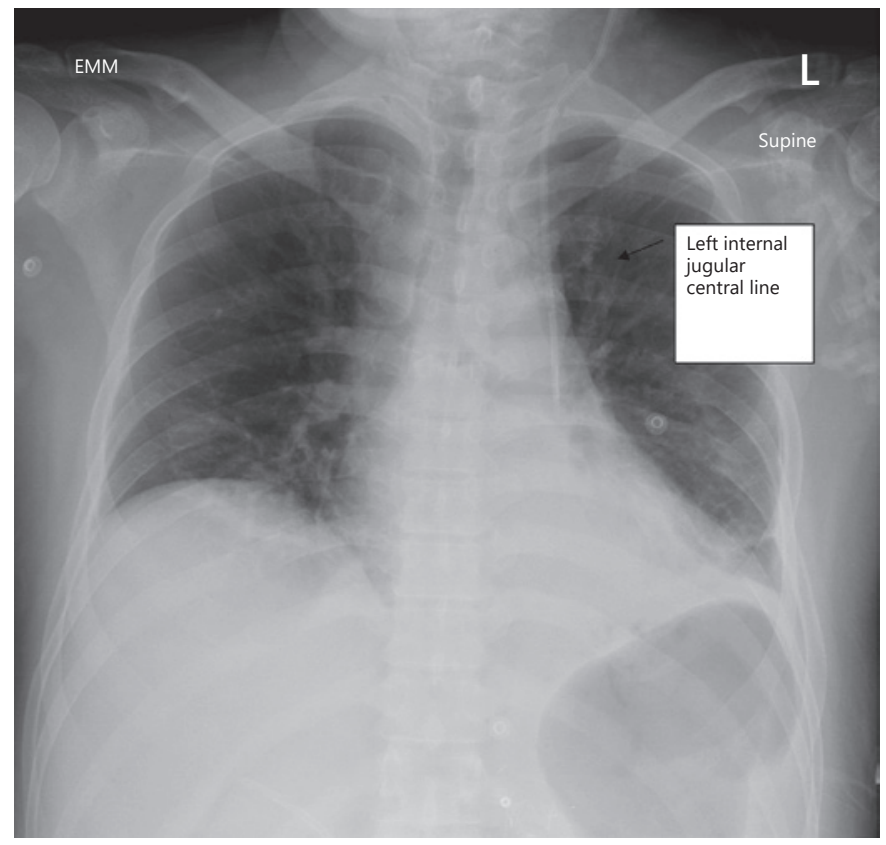

Fig. 1. Initial chest X-ray on day 1 showing abnormal path of left internal jugular central line.

Fig. 2. CT-chest PLSVC draining to the coronary sinus. CT, computed tomography; PLSVC, persistent left superior vena cava.

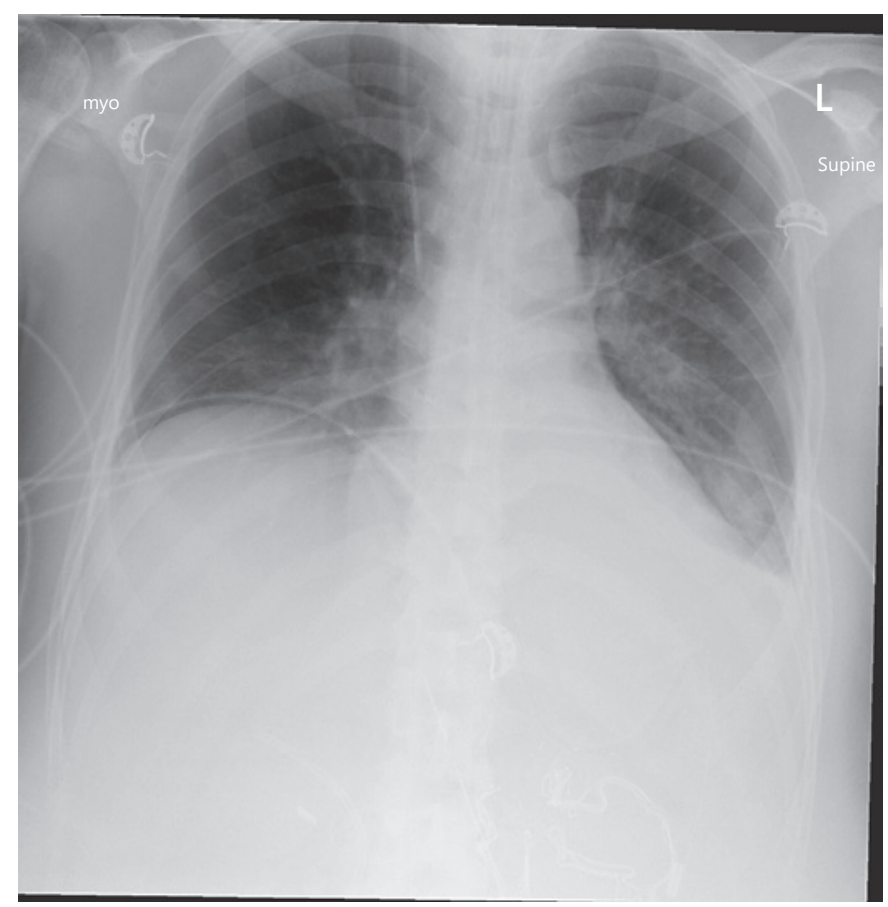

Fig. 3. Right internal jugular cannulation on day 3 after removal of the left central line.

Malpositioning of Left Internal Jugular Central Line

\section{2}

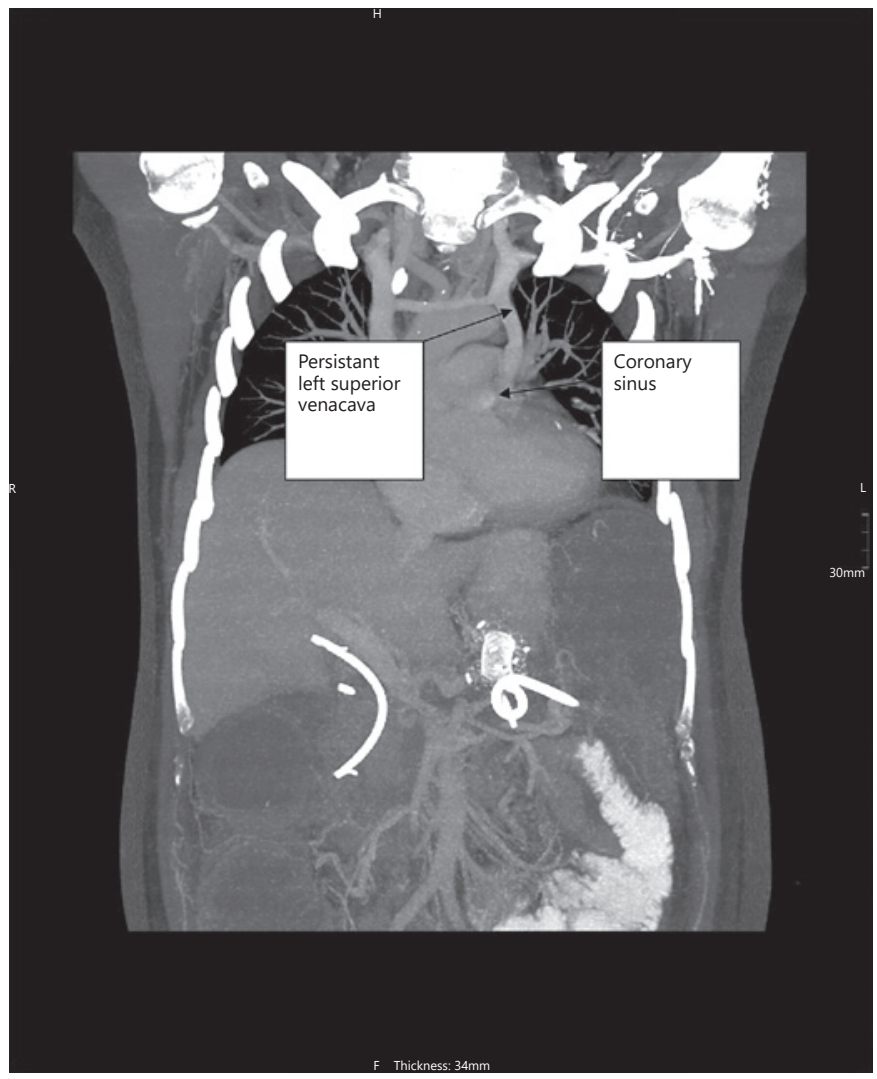

As per information furnished by the family, the patient never had any cardiac signs and symptoms. The line was changed to the right internal jugular central line to measure the central venous pressure as it was unreliable on the left side on day 3 (Fig. 3). The insertion of right central line was uneventful. Postoperative transthoracic echocardiography was done, which did not reveal any cardiac anomalies.

\section{Discussion}

A left-sided SVC is an incidental finding found usually during central line insertion as per our case. It forms during normal foetal development due to failure of obliteration of anterior cardiac vein [2]. The PLSVC passes anterior to the left hilum and lateral to aortic arch. Most commonly, this vein drains into coronary sinus $82-90 \%$ can be seen in our patient CT-chest (Fig. 2) and left atrium in $8 \%$.

As far as concerned, it is safe to use central line for drug administration not for central venous pressure measurement. Other complications resulting from the existence of PLSVC include difficulty in pulmonary artery catheterization, cerebral abscess, arrhythmia, and thromboem- 
bolic events [3-5]. It is also worth mentioning that the incidence of defects in foetuses is higher than in the general population. This is due to the anatomical anomalies that may cause spontaneous miscarriage, as well as the existence of PLSVC along with other heart defects that may lead to premature death $[4,6]$.

The most common congenital heart diseases associated with left SVC are Tetralogy of Fallot, anomalous pulmonary vein, and coarctation of aorta [1]. It was an incidental finding during the procedure as our patient was asymptomatic and even the vein was draining into the coronary sinus as seen in the CT-chest (Fig. 2). The differential diagnoses of the left para-mediastinal catheter are PLSVC, left superior intercostal vein, and left pericardiophrenic vein. The malposition is usually noticed during left central line insertion. It is of utmost importance to us to identify such unusual path and to identify any co-existing cardiac abnormalities if suspected. PLSVC is very often discovered accidentally during invasive cardiac procedures, mostly during routine left-sided rightheart catheterization and surgical procedures [7]. Malpositioning of the central line like kinking inside the internal jugular vein, migration to the subclavian vein, and the external jugular vein has been reported $[8,9]$.

\section{Conclusion}

The abnormal path taken by the central line in view of PLSVC is an incidental finding during central line insertion, which is safe to administer lifesaving drugs. It is unreliable for central venous pressure measurement. We should always rule out congenital cardiac anomalies in such patients by transoesophageal echocardiography by cardiac MRI. There are many cases where the central line has taken unusual malpositioning in both left and right internal jugular cannulation, but PLSVC is a concern in view of deranged haemodynamics in small percentage of patients which need to be addressed appropriately in perioperative period.

\section{Acknowledgements}

We thank the departments of Anaesthesia and Radiology.

\section{Statement of Ethics}

Written consent was obtained from the patient's family.

\section{Conflict of Interest Statement}

There are no conflicts of interest.

\section{Funding Sources}

The authors did not receive any funding.

\section{Author Contributions}

R.R.M. - compiling the entire case report and collecting images. H.F.Z. - editing and compiling the final case report. N.K.M. - image reporting and editing.

\section{References}

1 Tyrak KW, Hołda MK, Koziej M, Piątek K, Klimek-Piotrowska W. Persistant left superior venacava. Cardiovasc J Afr. 2017 May 23; 28(3):e1-e4.

2 Miraldi F, di Gioia CR, Proietti P, De Santis M, d'Amati G, Gallo P. Cardinal vein isomerism: an embryological hypothesis to explain a persistent left superior vena cava draining into the roof of the left atrium in the absence of coronary sinus and atrial septal defect. Cardiovasc Pathol. 2002;11(3):149-52.

3 Lee MS, Pande RL, Rao B, Landzberg MJ, Kwong RY. Cerebral abscess due to persistent left superior vena cava draining into the left atrium. Circulation. 2011;124(21):2362-4.
4 Sarodia BD, Stoller JK. Persistent left superior vena cava: case report and literature review. Respir Care. 2000;45(4):411-6.

5 Lai YC, Goh JC, Lim SH, Seah TG. Difficult pulmonary artery catheterization in a patient with persistent left superior vena cava. Anaesth Intensive Care. 1998;26(6):671-3.

6 Pasquini L, Belmar C, Seale A, Gardiner HM. Prenatal diagnosis of absent right and persistent left superior vena cava. Prenat Diagn. 2006;26(8):700-2.
7 Elison B, Evans D, Zanders T, Jeanmonod R. Persistent left superior vena cava draining into the pulmonary venous system discovered after central venous catheter placement. Am J Emerg Med. 2014;32(8):943.

8 Solanki SL, Thota RS, Patil VP. Malpositioning of right internal jugular central venous catheter into right external jugular vein forming "figure of eight". Ann Card Anaesth. 2015 Jul-Sep;18(3):414-5.

9 Dinasarapu CR, Adiga GU, Malik S, Abdo F, Patel M. Recurrent cerebral embolism associated with indwelling catheter in the presence of anomalous neck venous structures. South Med J. 2010;103(8):845-3. 